\title{
EVALUATION OF A TRANSFER OF CONTROL CONCEPT FOR AIRBORNE SELF-SEPARATION
}

\author{
Hans-Juergen Hoermann, Dirk Schulze-Kissing \& Oliver Zierke \\ German Aerospace Center (DLR), Hamburg, Germany
}

\begin{abstract}
Airborne self-separation is one of the concepts which is currently under discussion as a key feature in NextGen/SESAR's future air-transport system. Self-separation of aircraft is expected to provide higher capacity and safety levels as well as a better consideration of the different needs of airspace users. However, in order to become operational self-separation requires certain airspace structures and procedures. Compared to earlier studies by FAA and NASA which are based on the concept of shared control by ATC and flight crews, our approach uses a transfer of control concept where the control authority for aircraft separation tasks is shifted from ATC to flight crews and back to ATC. In order to better understand possible roles and role changes of future aviators, we conducted an integrated simulation study with 15 airline pilots and five air-traffic controllers on a low-cost simulation platform called AviaSim. In an experimental design with repeated measurements, the subjects flew three scenarios with and without control shift for self-separation. The findings show that operators' workload and situation awareness scores are better balanced under the shift-of-control condition compared to the traditional ground-control condition. Additionally, effects of transfer of control on preferred separation tactics and safety indicators are examined.
\end{abstract}

\section{INTRODUCTION}

The European master plan for future ATM (SESAR, 2008) is committed to operational concepts of self-separation by using airborne separation assurance systems (ASAS). Selfseparation is based on the concept of free flight, which is defined as "a safe and efficient flight operating capability under instrument flight rules in which the operators have the freedom to select their path and speed in real time" (RTCA, 1995). According to RTCA (1995), free flight requires airborne self-separation and its monitoring on the ground. Functionally, ASAS is the main technical prerequisite to migrate separation assurance tasks from ground to air. Assistance systems are essential elements of ASAS, e.g. the Cockpit Display of Traffic Information (CDTI) which visualizes other aircraft's positions and intentions to the flight crews, or conflict detection and alerting systems for air-traffic controllers (ATCO). Adequate concepts of operation are currently under scrutiny within NextGen and SESAR programs.

A significant amount of research has been carried out to evaluate specific effects of airborne self-separation on human performance issues of pilots and ATCOs (Endsley, Mogford, \& Stein, 1997; Metzger \& Parasuraman, 2001; DiMeo et al., 2002), on capacity gains (Mogford \& Kopardekar, 2004) and on operational risks (Trouslard, Kircher \& Boudes, 2005; Blom, Obbink \& Bakker, 2007). These studies have found that airborne self-separation can be very effective, but also has its limitations for dense traffic conditions when conflict resolution is reached in a sequential and uncoordinated manner (Blom et al., 2007). Research regarding the FAA concept of shared separation (DiMeo et al., 2002) as well as the NASA concept of distributed traffic management (Mogford \& Kopardekar, 2004) has repeatedly found that
ATCOs reported some safety concerns and a higher workload under shared separation conditions due to increased monitoring and perceived lack of timely pilot intent knowledge. The pilot participants, however, preferred shared separation conditions, particularly the condition in which they had the highest level of separation responsibility. Apparently, the perceived flexibility that shared separation provided for the pilots seemed to result in safety concerns and discomfort for the controllers (DiMeo et al., 2002).

Goals of this study: A first experiment from a series of studies aiming at analysing work roles of ATCOs and pilots in the future ATM system is reported. Instead of shared separation responsibilities, the concept of transfer of control is examined. In principle, transfer of control during selfseparation means that the ATCO is not forced into a passive monitoring role. When control authority is shifted to the flight deck for the self-separation mode, (limited) ATC services are available only upon request. The effects of transfer of control on levels of situation awareness and workload of the operators are analysed. The level of safety is expected to increase or to be maintained compared to traditional ground controlled traffic separation.

\section{METHOD}

\section{Participants}

20 male operators participated in the study, of whom five were centre controllers of the German ANSP with an average work experience of 30 years and 15 were licensed airline pilots with an average experience of 1394 flight hours. The mean age of the operators was 32 years. The study is part of the DLR project AVIATOR 2030 (Eissfeldt et al., 2009). 
Paper presented at the 54th Annual Meeting of the Human Factors and Ergonomics Society. San Francisco/CA, Sep 27 - Oct 1, 2010.

\section{Material}

Simulator. A simulation platform, called AviaSim (Hoermann, Schulze-Kissing \& Zierke, 2009) was designed to meet requirements of high realism at low costs, high adaptability, and controllability for experimental applications. With an open LAN architecture, AviaSim is currently configured for one controller position and up to eight connected cockpit positions. The AviaSim workstations are PC based and equipped with the necessary periphery for task performance. The ATC environment provides short-term conflict alert (STCA), mid-term conflict detection (MTCD) as well as data-link communication. The cockpit environment is basically that of a modern airline jet with an additional trafficvisualization system (Cockpit Display of Traffic Information, CDTI). The symbology used for the CDTI is based on the specifications made by Johnson et al. (1997) at NASA Ames. Additionally, a transparent window is projected onto the cockpit screen to display ATC instructions transmitted via data-link. All workstations are also equipped with headsets for voice communication.

Airspace Structure. The airspace sector is rectangular with a diagonal of $240 \mathrm{NM}$ and level bands from FL 240 to FL 400. The entry/exit fix-posts are positioned in a way that connecting routes create a three-line crossing near the centre of each of the four quadrants and a two-line crossing at the exact centre of the sector. The airspace used in the selfseparation condition is based on the same sector structure, but a rectangular free-flight zone of about $80 \mathrm{NM}$ diagonal was inserted into the sector centre with no route structure. Each corner of the free flight zone is marked as a triangular transition zone (TZ). For entering and leaving free flight, control authority is transferred stepwise within the TZ. The concept of a TZ as well as the system of rules for aircraft transitions from managed airspace (MAS) to free flight airspace (FFAS) are adopted e.g. from Beers \& Huismann (2002) and Ruigrok, de Gelder \& Scholte (2005).

Traffic Samples. Traffic samples are scripted according to flight plans which force the operators into situations of mutual merging and spacing within the transition zone. While being en-route through the sector, additional crossing traffic is encountered which requires further separation activity by ATC (managed flight condition without CDTI) or by pilots (self-separation condition with CDTI). The traffic for the two experimental conditions was made comparable by altering call-signs and the geometric relations without changing the spatio-temporal relations between the aircraft.

\section{Experimental Plan}

A two-factorial repeated measurement design was used. The independent variable was the control authority for flights within the sector, with the two levels 'MAS - no CDTI' (one run per trial) and 'FFAS - CDTI available' (two runs per trial). The second independent variable was the position 'ATCO' versus 'pilot'.

\section{Experimental Procedure}

Subjects were examined in groups of four, each with one controller and three pilots. During the simulation trials participants were seated in separate rooms. The first day of each two-day session began with familiarization and rehearsal of the in-advance information. Controllers were instructed to communicate primarily via data-link. Pilots were briefed to expect data-link instructions from ATC. As the simulated cockpits did not provide a data-link input device, pilots had to use the voice channel to read back ATC-instructions and as well as for aircraft-to-aircraft communication under free flight. The first day ended with a one-hour joint scenario training run. The second day began with an introduction of the $\mathrm{TZ}$ concept and the system of rules for transitions from MAS to FFAS and vice versa. Then three en-route scenarios with duration of about 45 minutes each were exercised jointly. In the so-called baseline scenario the traffic was managed entirely by ATC (managed flight condition without CDTI). In two self-separation scenarios the airspace included the TZ and FFAS, in which pilots were free to select their path and speed in real time (self-separation condition with CDTI). The scenario sequence was rotated from group to group. At the beginning of each scenario, the three piloted aircraft as well as over 20 'synthetically scripted' aircraft were positioned airborne outside the sector boundaries. During the course of each scenario, the sector was gradually filled with 24 aircraft coming from four different directions (northeast, northwest, southeast and southwest). Each scenario was frozen five times to allow instantaneous self-assessments for the following phases: (a) Entry, (b) Merging, (c) Crossing, (d) Fanning, (e) Exit. Each scenario ended with the hand over of piloted aircraft to the neighbouring sectors.

\section{Instruments}

After each scenario the participants filled out the NASA Task Load Index, NASA-TLX (Hart \& Staveland, 1988) and the Situation Awareness Rating Technique SART (Taylor, 1990) to assess controllers' and pilots' workload and situation awareness during the scenarios. After completing the last simulation run, an additional questionnaire was handed out to assess the acceptability of both the simulation environment as well as the scenarios used. To assess the gradient of workload and situation awareness during a simulation run, two scales for instantaneous self-assessment (ISA with 3-point scales) were administered for immediate assessment during five scenario freezes. In order to simplify comparison of the two experimental conditions, the rating scores for both selfseparation scenarios were combined into mean scores. Additionally, simulation log files were analysed for the amount and timing of controllers' aircraft separation instructions. Safety level was assessed by the total number of losses of separation, as well as by the total number of STCAs. 
Paper presented at the 54th Annual Meeting of the Human Factors and Ergonomics Society. San Francisco/CA, Sep 27 - Oct 1, 2010.

\section{Hypotheses}

The experimental setup was assumed to be sensitive to effects of self-separation on pilots' and controllers' workload and situation awareness. We expected both NASA-TLX and SART as well as ISA scores to be more favourable for the level of human performance during self-separation conditions (i.e. higher situation awareness and medium workload is expected). At the same time, the level of safety should be enhanced or at least be maintained. Plausibility of effects could be interpreted as a first indication that the simulation environment is a suitable platform for future operational concept validations.

\section{RESULTS}

There is clear evidence that under traditional ATC managed flight separation conditions in the baseline scenario ATCOs score significantly higher on workload than in the self-separation scenario, when control authority is shifted to the flight deck $(\mathrm{F}(1,4)=9.1, \mathrm{p}<0.05)$. Workload increases conversely for pilots in the self-separation condition ( $\mathrm{F}(1,14)$ $=5.8, \mathrm{p}<0.05$ ). However, as shown in Table 1 , the workload distribution between ATCOs and pilots is overall better balanced in the self-separation scenario. In the baseline scenario, ATCOs reported a very high workload level (scoring 73 out of 100) while pilots seemed to be rather underloaded. A detailed analysis of the NASA-TLX workload factors shows that the increasing workload for the pilots resulted from higher mental demands under self-separation conditions. In contrast, ATCOs reported decreasing temporal demands when the aircraft were self-separating.

Table 1: Mean values for workload and situation awareness under baseline and self-separation conditions. Standard deviations in brackets.

\begin{tabular}{|c|c|c|c|}
\hline \multirow{2}{*}{\multicolumn{2}{|c|}{ Independent Variables }} & \multicolumn{2}{|c|}{ Dependent Variables } \\
\hline & & NASA- & \\
\hline \multirow{3}{*}{ Baseline } & & 73.1 & 26.5 \\
\hline & & $(16.2)$ & $(17.1)$ \\
\hline & Pilots & $\begin{array}{c}26.2 \\
(14.7)\end{array}$ & $\begin{array}{c}46.8 \\
(14.1)\end{array}$ \\
\hline \multirow{2}{*}{$\begin{array}{c}\text { Self- } \\
\text { separation }\end{array}$} & ATCOs & $\begin{array}{c}52.3 \\
(24.2)\end{array}$ & $\begin{array}{c}35.0 \\
(19.7)\end{array}$ \\
\hline & Pilots & $\begin{array}{c}37.6 \\
(17.3)\end{array}$ & $\begin{array}{c}45.0 \\
(12.6)\end{array}$ \\
\hline
\end{tabular}

The SART total score does not show a significant difference between the two scenario types. Pilots remain on a rather high SA level. ATCOs show a non-significant increase $(p=0.27)$. However, the SART sub-dimensions for "Demand of Attentional Resources" (F $(1,4)=11.9$, p < 0.05) and "Supply of Attentional Resources" $(\mathrm{F}(1,4)=10.2$, $\mathrm{p}<0.05)$ both decrease significantly for ATCOs. Pilots show an increase on exactly the same sub-dimensions $(\mathrm{F}(1,14)=11.3$, $\mathrm{p}<0.01$ and $\mathrm{F}(1,14)=11.4, \mathrm{p}<0.01$ for the respective dimensions). The SART sub-dimension "Understanding of the Situation" does not differ between the two experimental conditions. These changes in SA seem to be directly related to the shift of task demands from ground to air in the selfseparation mode.

This picture is confirmed by the ISA Workload ratings for each of the five scenario phases (see Figure 1). For ATCOs, the workload peak during crossing traffic (phase 3) decreases significantly $(F(1,4)=20.2, \mathrm{p}<0.05)$ when aircraft are self-separating, whereas for the pilots the workload ratings increase significantly during the entry $(\mathrm{F}(1,14)=7.0, \mathrm{p}<$ $0.05)$ and merging traffic phases $(\mathrm{F}(1,14)=4.0, \mathrm{p}<0.07)$. This increase of workload for pilots during the first two scenario phases could be a consequence of the shift of control authority and the increased demand to plan a suitable flight path through the FFAS in good time with maximal avoidance of conflicting traffic.

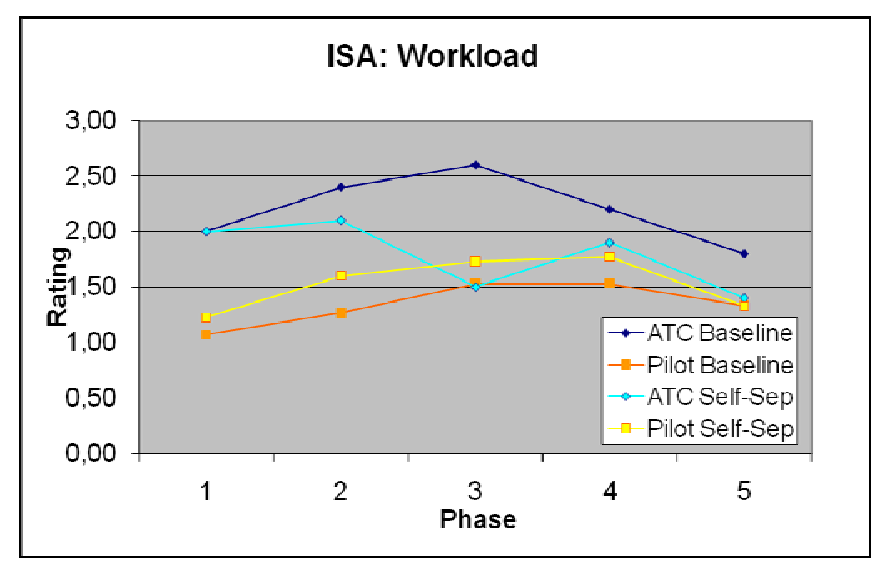

Figure 1: Results of ISA workload ratings across the five scenario phases (1=Entry, 2=Merging, 3=Crossing, 4=Fanning, 5=Exit)

Within groups, the ISA Situation Awareness ratings differ significantly for both ATCOs $(p<0.01)$ and pilots $(p=0.06)$ during the scenario phase of crossing traffic (phase 3 ). On the $10 \%$ level, the ISA-SA ratings for controllers in phase 1, 4, and 5 are also significantly higher during the self-separation scenario than under baseline conditions. In summary, the ISA ratings for SA seem to remain on a rather high level for pilots while they obviously increase for ATCOs throughout the selfseparation mode. Increased task demands are reflected by the SA ratings of pilots only during the crossing traffic phase (see Figure 2). 
Paper presented at the 54th Annual Meeting of the Human Factors and Ergonomics Society. San Francisco/CA, Sep 27 - Oct 1, 2010.

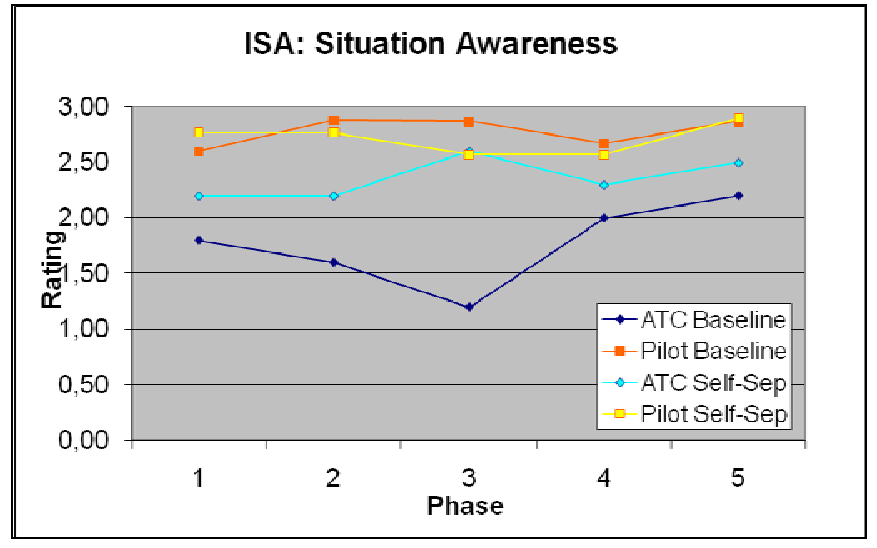

Figure 2: Results of ISA situation awareness ratings across the five scenario phases (1=Entry, 2=Merging, 3=Crossing, 4=Fanning, 5=Exit)

Comparisons of data from the simulator log files complement some interesting factual information about ATCO separation tactics and the overall safety level. In the experimental trials, a total of $\mathrm{N}=11$ losses of separation (LOS), $\mathrm{N}$ $=11$ separation regains, and $\mathrm{N}=45$ STCAs are recorded. The distribution of these occurrences differs noticeably across the three experimental runs in each group. While the lowest safety performance is registered for the first self-separation run, the best safety performance is observed for the second selfseparation run. While the baseline scenario has a total of 18 STCAs and 2 LOS, during the second self-separation scenario only 6 STCA and 1 LOS are recorded. Obviously, some positive learning transfer took place over the entire session. A look at the separation instructions delivered by ATCOs reveals that the number of instructions increases from the first to the second self-separation scenario. Additionally, these separation instructions occur at a much earlier point in time there. It looks as if ATCOs successfully adopted a longer planning horizon for their separation tactics to avoid later conflicts between the aircraft.

\section{DISCUSSION}

It is shown that taking advantage of the low cost simulation platform AviaSim can provide important data to better understand human factors issues in procedure design and concept evaluation for the future air-transport system. With the experimental setup, effects of self-separation on pilots' and controllers' workload and situation awareness can be identified. As expected, measures of workload and situation awareness are obviously more favourable for human performance during self-separation conditions (i.e. higher situation awareness and medium workload in the selfseparation scenario). This seems to be an improvement compared to shared-separation concepts. With respect to the level of safety it is found that the transfer-of-control concept implemented here for the self-separation mode clearly requires more proactive separation instructions by ATC before the aircraft transit from MAS into FFAS. From the flight-deck point of view, the CDTI and free routing concepts are well accepted and do not lead to task overload. Further studies are scheduled at DLR for the following years to investigate different levels of risk tolerance during traffic separation depending on where the control authority is located.

According to these findings it can be assumed that adequately trained ATCOs can use the spare mental capacity which they gain under self-separation conditions to anticipate traffic flow and take appropriate measures to proactively avoid conflicts that may emerge in the FFAS.

\section{ACKNOWLEDGEMENTS}

This study was carried out within the DLR project AVIATOR 2030. The authors express their gratitude to Lufthansa German Airlines, DFS Deutsche Flugsicherung GmbH, and the DLR Program Directorate for Aeronautics for the support.

\section{REFERENCES}

Beers, C. S. \& Huismann, H. (2002). Transition between Free-Flight Airspace and Managed Airspace Amsterdam: National Aerospace Laboratory (NLR).

Blom, H.A.P., Obbink, B.K. \& Bakker, G.J. (2007). Safety risk simulation of an airborne self-separation concept of operation. Proceedings 7th AIAA-ATIO Conference, September 18-20, Belfast, Northern Ireland.

DiMeo, K., Sollenberger, R., Kopardekar, P., Lozito, S., Mackintosh, M. A., Cardosi, K. \& McCloy, T. (2002). Air-ground integration experiment (Rep. No. DOT/FAA/CT-TN02/06). Atlantic City, NJ: FAA.

Eissfeldt, H., Grasshoff, D., Hasse, C., Hoermann, H.-J., Schulze Kissing, D., Stern, C., Wenzel, J. \& Zierke, O. (2009). Aviator 2030 - Ability Requirements in Future ATM Systems II: Simulations and Experiments. DLRForschungsbericht 2009-28, Cologne, Germany: DLR.

Endsley, M.R., Mogford, R.H. \& Stein, E.S. (1997). Controller situation awareness in free flight. In Proceedings of the Human Factors and Ergonomics Society 41st Annual Meeting Santa Monica, CA: Human Factors and Ergonomics Society, pp. 4-8.

Hart, S.G. \& Staveland, L. E. (1988). Development of NASATLX (task load index). Results of theoretical and empirical research. In P.A. Hancock \& N. Meshkati (Eds.), Human Mental Workload. North Holland: Elsevier, pp. 139-183.

Hoekstra, J.M., Ruigrok, R.C.J. \& van Gent, R.N.H.W. (200). Free flight in a crowded airspace? Paper presented at the 3rd USA/Europe ATM R\&D Seminar, Napoli, June 2000.

Hoermann, H.-J., Schulze Kissing, D. \& Zierke, O. (2009). Determining job requirements for the next aviator 
Paper presented at the 54th Annual Meeting of the Human Factors and Ergonomics Society. San Francisco/CA, Sep 27 - Oct 1, 2010.

generation. In Proceedings of the 15th International Symposium of Aviation Psychology, pp. 113-118, April 27-30, 2009.

Johnson, W.W., Battiste, V., Dezell, S., Holland, S., Bleche, S. \& Jordan, K. (1997). Development and demonstration of a prototype free flight cockpit display of traffic information. SAE Transactions, 106, 1566-1582.

Metzger, U. \& Parasuraman, R. (2001). The role of the air traffic controller in future air traffic management: An empirical study of active control versus passive monitoring. Human Factors, 43, 519-528.

Mogford, R. \& Kopardekar, P. (2004). Air traffic management system development and integration (ATMSDI): Joint NASA Ames/Langley DAG-TM Simulation. Final Report. AATT MS 8.503.11 \& MS 8.503.12. September 2004. Moffett Field/CA: NASA Ames.

RTCA (1995). Final report of RTCA task force 3 - free flight implementation. Washington, DC: RTCA Inc.

Ruigrok, R.C.J., de Gelder, N. \& Scholte, J.J. (2005). Pilot perspective of ASAS self-separation in challenging environments. Paper presented at the 6th USA/Europe ATM R\&D Seminar, Balitmore, June 2005.

SESAR (2008). SESAR Master plan D5. DLM-0710-01-0200. Brussels, April 2008.

Taylor, R.M. (1990). Situation awareness rating technique (SART): The development of a tool for aircrew systems design. In Situational awareness in aerospace operations (AGARD-CP-478), Neuilly Sur Seine: NATO-AGARD, 1990.

Trouslard, P., Kircher, T. \& Boudes, N. (2005). Simulated free routing operations in the Marseille UIR: Results and issues from human factors perspective. Paper presented at the 6th USA/Europe ATM2005 R\&D Seminar. 